\title{
EVALUASI GEOMETRI JALAN ANGKUT TAMBANG PADA PT. MANAKARRA MULTI MINING PROVINSI SULAWESI BARAT
}

\author{
${ }^{1}$ Habibie Anwar, ${ }^{2}$ Nurliah Jafar, ${ }^{3}$ Alam Budiman Thamsi, ${ }^{4}$ Muh. Idham Farid \\ 1,2,3,4 Jurusan Teknik Pertambangan Fakultas Teknologi Industri Universitas Muslim Indonesia \\ Jln Urip Sumoharjo KM 5 Kampus 2 UMI. Telp: 081341638063. \\ Email : hbbnwr@umi.ac.id
}

\begin{abstract}
A good mining road was the road with a geometric shape convenient as the company standards. The purpose of this study was to determine the geometrical conditions of hauling roads in PT Manakarra Multi Maning, whether these were in accordance with standards or not. Stages of road geometry data collection started with the measurement of the dimensions of the road using GPS and Compass. The next step was processing the data from the survey tool using software to determine the dimension value of the mine road according to AASHTO standards. Based on the results of the calculation of this study, it could be concluded that the width of the haul road on the straight road at all stations is 12 meters - 13 meters, and it had met the specified minimum standard of 9 meters. The width of the road at the bend was based on the results of calculations for the width of the road at the bend at each station that is 12 meters - 14 meters, and the road met the specified minimum standard of 12 meters. The actual road superelevation did not meet the standards of $1.3 \%$ and $9 \%$, while the standards set for minimum superelevation 4\% and maximum superelevation $8 \%$. The actual slope of the road that did not meet the maximum standard $10 \%$, where the actual slope of the existing road in the field was relatively bigh at $11 \%$ to $15 \%$.
\end{abstract}

Keywords: AASHTO, Mamuju, Mining road, Superelevation

\begin{abstract}
Abstrak
Jalan tambang yang baik adalah ketika memiliki bentuk geometri jalan yang sesuai standar yang ditetapkan oleh perusahaan. Tujuan dari penelitian ini adalah untuk menghitung kondisi geometri jalan tambang di PT Manakarra Multi Mining, apakah sudah sesuai dengan standar. Tahap pertama yang dibutuhkan yaitu mencari data geometri jalan dan dimensi jalan dengan memakai kompas dan GPS. Tahap kedua yaitu menghitung hasil dari peralatan survei dengan alat bantu berupa software untuk mendapatkan nilai dimensi sesuai standar AASHTO. Berdasarkan hasil dari perhitungan penelitian ini dapat disimpulkan lebar jalan angkut pada jalan lurus di semua stasiun yaitu 12 meter sampai 13 meter, dan telah memenuhi standar minimum yang ditetapkan yaitu 9 meter. Lebar jalan tikungan dari hasil persamaan untuk lebar jalan tikungan di setiap stasiun yaitu 12 meter sampai 14 meter, dan telah jalan memenuhi standar minimum yang ditetapkan yaitu 12 meter. Superelevasi jalan aktual tidak memenuhi standar yaitu 1,3\% dan 9\%, sedangkan standar yang ditetapkan untuk superelevasi minimum 4\% dan superelevasi maksimum 8\%. Kemiringan jalan aktual yang tidak memenuhi standar maksimum 10\%, dimana kemiringan jalan aktual yang ada di lapangan relatif tinggi yaitu 11\% hingga $15 \%$.
\end{abstract}

Kata Kunci : AASHTO, Jalan tambang, Superelevasi, Mamuju

\section{PENDAHULUAN}

Perusahaan pertambangan merupakan perusahaan sangat membutuhkan dana yang besar. Agar segala usaha pertambangan dapat hasil yang besar selanjutnya dilakukan perancangan jalan secara benar sebelum usaha pertambangan dikerjakan. Laba yang diinginkan akan didapatkan bersama dengan raihan rencana produksi yang diputuskan oleh tiap-tiap perusahaan di bidang pertambangan. Setiap kali pada pengoperasian jalan di tambang kita harus berpatokan pada standar-standar yang di tetapkan pada perusahaan maupun standar AASTHO, Jalan pada tambang berguna sebagai penyambung antara daerah lain dengan area crushing plant, pengolahan galian tambang, gedung perkantoran, mess pekerja, serta daerah-daerah yang ada di sekitar pertambangan (Rauf, A. 1998).

Desain jalan di area tambang pada umumnya mempunyai kesamaan pada jalan angkut yang ada di kota besar pada umumnya, Perbandingan yang sangat dapat dilihat berada di muka jalan pada lapisan permukaan jalannya seperti jalan yang ada di kota pada umumnya beraspal atau permukaannya berbeton, karena jalan tambang sering kali di lalui alat-alat berat. Keadaan jalan tambang yang tidak cocok dengan standar yang berlaku akan mempengaruhi ketidaknyamanan mekanik alat yang bertugas untuk melintasi jalan serta infrastruktur jalan yang ada, produktivitas umur pada alat dapat berpegaruh pada aktivitas kinerja alat angkut yang beroperasi dan sehingga dapat berpotensi menyebabkan kejadian yang tidak diinginkan yang terjadi pada tambang. Maka dari itu, kita dapat melakukan riset atau penelitian terhadap kondisi jalan di area tambang (Aldiyansyah \& Husain 2016). 
Target produksi yang dinginkan bisa tercapai jika kondisi jalan sesuai dengan standar yang dapat digunakan dalam produksi (Pelu 2018). Jalan tambang yang baik apabila memiliki bentuk geometri jalan yang sesuai standar AASTHO, sehingga dapat memberikan rasa aman kepada pemakai jalan. Dimensi lebar jalan, dimensi tikungan, superelevasi, grade, cross slope, dan tanggul pengaman merupakan bagian yang perlu diperhatikan agar jalan tambang sesuai standar yang di tetapkan (Pelu, 2018).

Namun sering di jumpai pada jalan angkut tambang front metode penambangan menuju desposal pada lokasi area penambangan berdasarkan data departemen Engineering PT Manakarra Multi Mining ada beberapa segmen jalan yang travel speed yang dapat di lalui damp truck Hino 500 FM 260 JD sehingga prosedur alat angkut dapat dihitung produktivitas alat yang beroprasi karna itu butuh evaluasi megenai jalan tersebut (Lambung, Saismana dan Hakim 2016).

\section{Tujuan Penelitian}

Tujuan penelitian adalah mengevaluasi geometri jalan angkut menurut standar AASTHO pada PT Manakarra Multi Mining di Kecamatan Bonehau, Kabupaten Mamuju Provinsi Sulawesi Barat

\section{Metode Penelitian}

Metode penelitian yang dilakukan di lapangan yaitu dengan mengukur lebar jalan, jari-jari tikungan, kemiringan jalan dan lain-lain. Dari hasil pengukuran ini lalu di olah di komputer dengan mengunakan perangkat lunak untuk mendukung proses pembuatan jalan tambang, proses ini mungkin sangat berpatokan pada kondisi hasil yang ada dilapangan sehingga dapat menghasilkan data yang sempurna (Direktorat Jenderal Bina Marga. 1997)

Perhitungan pada jalan lurus dan tikungan serta pengukuran pada jalan tambang, pada perhitungan ini menggunakan persamaan [1]

$$
\begin{aligned}
& L(\min )=[(n . W t)+\{(n+1)(0,5 . W t)\}] \ldots \ldots \ldots . . .[1] \\
& \text { keterangan: }
\end{aligned}
$$

$\begin{array}{lll}\mathrm{L}(\mathrm{min}) & = & \text { lebar jalan minimum pada jalur lurus }(\mathrm{m}) \\ \mathrm{Wt} & = & \text { lebar } 1 \text { unit (alat) angkutan }(\mathrm{m}) \\ \mathrm{n} & & \text { jumlah lajur }\end{array}$

Perhitungan lebar jalan di tikungan untuk beberapa titik pengukuran dilakukan secara manual yaitu dengan menerapkan alat ukur meteran dengan mengukur beberapa jalan yang terdapat tikungan atau jalan hauling, untuk mengetahui nilai dari lebar jalan ini menggunakan metode Hartman \& Howard (1987) dengan persamaan [2]

$$
\begin{aligned}
& \left.W_{\text {min }}=\{2 .(U+F a+F b+Z))+C\right\} \\
& Z=\{(U+F a+F b / 2\}
\end{aligned}
$$

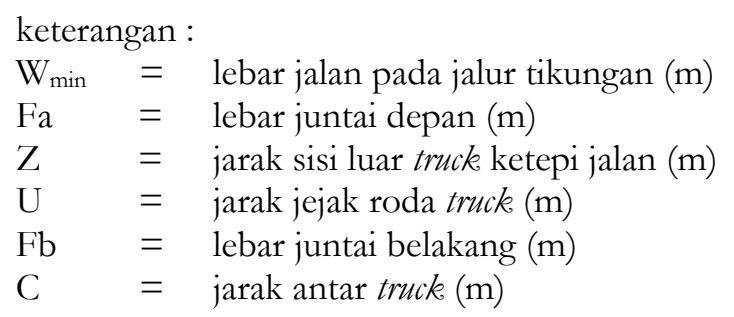

Semakin tinggi nilai superelevasi, maka akan semakin baik dan nyaman bagi driver untuk mengemudikan kendaraannya ditikungan dengan kecepatan tinggi. Namun praktek ini sudah tidak praktis lagi, karena nilai superelevasi yang terlalu besar (di atas $8 \%$ ) yang akan menyebabkan dampak buruk dari jalan, yaitu terkikisnya kerikil jalan oleh ban pada saat kecepatan tinggi. Berikut ini adalah persamaan [3] untuk mencari nilai superelevasi aktual di lapangan: 
$E_{\max }=\frac{\Delta h}{\Delta x} \times 100 \%$

keterangan :

$\mathrm{E}_{\max }=$ nilai superelevasi

$\Delta \mathrm{h}=$ beda tinggi antara 2 titik yang diukur (kiri dan kanan) $(\mathrm{m})$

$\Delta \mathrm{x}=$ jarak datar antara 2 titik yang diukur $(\mathrm{m})$

Perhitungan kemiringan memanjang dengan menggunakan metode kaufman and Ault (1997) dengan persamaan [4] :

$$
\text { Grade }=\left(\frac{\text { BedaTinggi }}{\text { Jarak }}\right) \times 100 \%
$$

keterangan :

Grade $=$ kemiringan memanjang $(\%)$

pada perhitungan ini dapat dilihat pada jarak yang di patokan pada setiap stasiun, pada pengolahan data jalan kemiringan tambang dapat dilihat dari bentuk kemiringan jalan yang ada dilapangan (Indonesianto, 2007).

Pada drainase dan tanggul dapat diamati pada area jalan front. Pegerasan jalan angkut dapat dilihat dari hasil jalan pegerasan jalan yang dilalui oleh pengendara yang lewat pada jalan tersebut agar tidak dapat menimbulkan kecelakaan pada saat kerja.

\section{HASIL DAN PEMBAHASAN}

\section{Spesifikasi Alat Angkut}

Jenis alat angkut yang digunakan pada PT Manakarra Multi Mining adalah dump truck Mitsubishi tipe 220PS 6x4, berikut adalah spesifikasi :
a. Jarak antara poros ban depan dan belakang : : 4,780 meter
b. Lebar juntai depan
c. Lebar juntai belakang (JA)
: 1,255 meter
d. Panjang keseluruhan kendaraan $(\mathrm{G})$
: 1,580 meter
e. Tinggi kendaraan $(\mathrm{O})$
: 8,265 meter
f. Lebar kendaraan (W)
: 3,245 meter
: 2,45 meter
g. Radius putar ban
: 8,8 meter

\section{Lebar Jalan}

a. Lebar Jalan Angkut di Jalan Lurus

Pada dasarnya jalan angkut dibuat untuk aktivitas alat transportasi dengan melihat spesifikasi alat angkut atau dump truck yang sering menggunakan atau melewati jalan tersebut. Berdasarkan data spesifikasi alat angkut yang ada, maka lebar jalan minimum (standar AASTHO) di tetapkan sebesar 9 meter, dari hasil pengukuran secara langsung di lapangan, dapat diketahui bahwa lebar jalan dari Blok $2 \mathrm{H}$ menuju stockpile pada PT Manakarra Multi Mining telah memenuhi standar minimum lebar jalan angkut yang telah ditetapkan (Nurhakim dan Saisman, 2016). 


\begin{tabular}{ccc}
\hline Stasiun & $\begin{array}{c}\text { Standar Lebar Jalan } \\
\text { Lurus minimum AASTHO } \\
(\mathbf{m})\end{array}$ & $\begin{array}{c}\text { Standar Lebar Jalan Lurus aktual } \\
\text { Perusahaan }(\mathbf{m})\end{array}$ \\
\hline 1 & 9 & 13 \\
2 & 9 & 12 \\
3 & 9 & 13 \\
4 & 9 & 13 \\
6 & 9 & 13 \\
8 & 9 & 12 \\
9 & 9 & 13 \\
10 & 9 & 12 \\
\hline
\end{tabular}

Pada tabel 1 memberikan gambaran standar operasional lebar jalan angkut di jalan lurus (gambar 1)

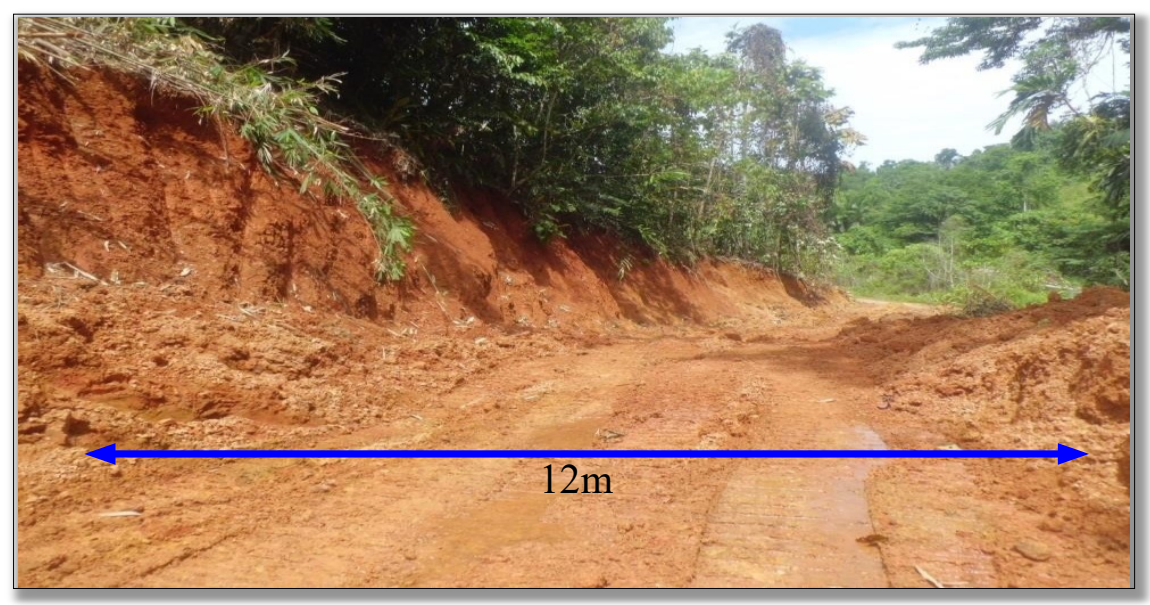

Gambar 1. Lebar jalan angkut di jalan lurus kondisi aktual

b. Lebar Jalan Angkut di Tikungan

Lebar jalan angkut pada tikungan sama halnya dengan penentuan lebar jalan lurus, penentuan lebar jalan pada jalur tikungan dapat dilihat dari alat angkut terbesar atau dump truck yang beroperasi di perusahaan yang sering atau melewati jalan tersebut. Berdasarkan tipe alat angkut, maka dapat menghasilkan jalan angkut minimum untuk 2 jalur sebesar 12 meter (Sutirja, Nurhalim dan Mustofa 2017).

Lebar jalan angkut di tikungan (gambar 2) untuk 2 jalur dapat dihitung dengan menggunakan persamaan [2]

Tabel 2. Lebar Jalan pada Tikungan

\begin{tabular}{ccc}
\hline Stasiun & $\begin{array}{c}\text { Standar Lebar Jalan Lurus } \\
\text { aktual Perusahaan }(\mathrm{m})\end{array}$ & $\begin{array}{c}\text { Standar Lebar Jalan Lurus minimum } \\
\text { AASTHO }(\mathrm{m})\end{array}$ \\
\hline 5 & 12 & 12 \\
7 & 13 & 12 \\
11 & 14 & 12 \\
14 & 13 & 12 \\
25 & 12 & 12 \\
30 & 12 & 12 \\
\hline
\end{tabular}




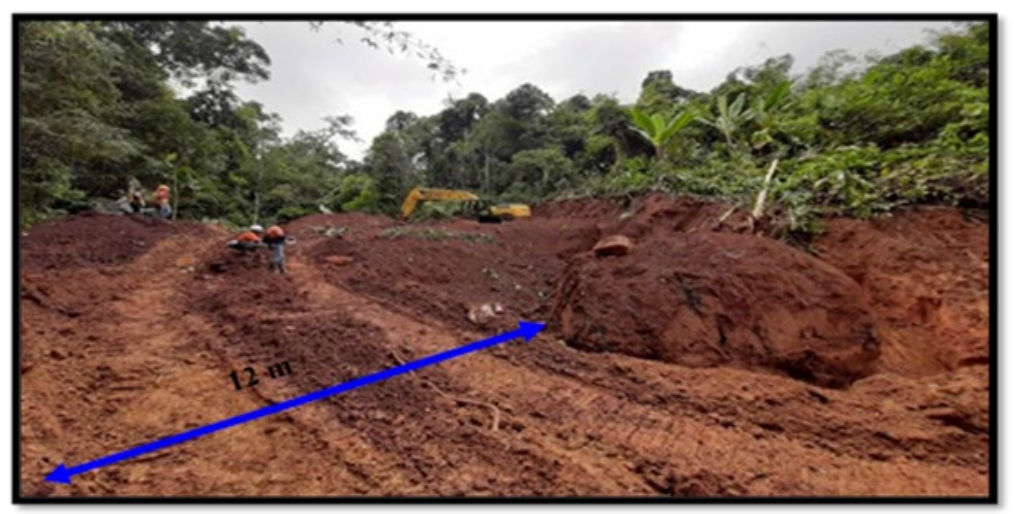

Gambar 2. Lebar tikungan pada jalan tambang

\section{Alinemen Horizontal}

a. Superelevasi dan Kecepatan Rencana

Untuk mencari nilai Superelevasi aktual, perlu melakukan pengukuran secara terbuka di lokasi telitian dengan menerapkan alat survei (total station dan prisma), kemudian data dari hasil survei tersebut. Untuk mencari nilai kecepatan rencana, nilai yang digunakan yaitu nilai aktual superelevasi dan nilai aktual jari-jari tikungan (Rahman, Nurhalim, dan Riswan, 2016).

Tabel 3. Superelevasi dan kecepatan rencana

\begin{tabular}{ccllllll}
\hline $\begin{array}{l}\text { Jari- } \\
\text { jari } \\
\text { Aktual }\end{array}$ & $\begin{array}{l}\text { Lebar } \\
\text { Jalan }\end{array}$ & $\begin{array}{l}\text { Elevasi } \\
\text { Sisi } \\
\text { Luar }\end{array}$ & $\begin{array}{l}\text { Elevasi } \\
\text { Sisi } \\
\text { Dalam }\end{array}$ & $\begin{array}{l}\text { Beda } \\
\text { Tinggi }\end{array}$ & $\begin{array}{l}\text { Jarak } \\
\text { Datar }\end{array}$ & $\begin{array}{l}\text { Elevasi } \\
\text { Aktual }\end{array}$ & $\begin{array}{l}\text { Kecepatan } \\
\text { Rencana } \\
\text { Aktual }\end{array}$ \\
\hline 74 & 12 & 937,405 & 939,788 & 0,379 & 13 & 2,9 & 17 \\
37 & 13 & 925,552 & 924,920 & 0,632 & 13 & 4,8 & 15 \\
35 & 14 & 921,625 & 920,360 & 1,265 & 14 & 9 & 20 \\
64 & 13 & 878,640 & 877,547 & 1,093 & 13 & 8 & 25 \\
165 & 12 & 856,073 & 855,921 & 0,152 & 12 & 1,3 & 17 \\
85 & 12 & 852,365 & 851,540 & 0,825 & 12 & 8 & 29 \\
\hline
\end{tabular}

Dari hasil pengolahan data (tabel 3), terdapat beberapa superelevasi aktual yang tidak memenuhi standar, dimana nilainya ada yang melebihi batas maksimum (8\%) dan ada pula yang kurang dari batas nilai minimum (4\%), merupakan rekomendasi superelevasi maksimum dan kecepatan rencana minimum untuk jari-jari tikungan aktual dilapangan. Rekomendasi penambahan nilai jari-jari tikungan, nilai superelevasi yang dibutuhkan terlalu tinggi dan melebihi batas standar superelevasi maksimum yang direkomendasikan oleh AASHTO 2001 yaitu $8 \%$.

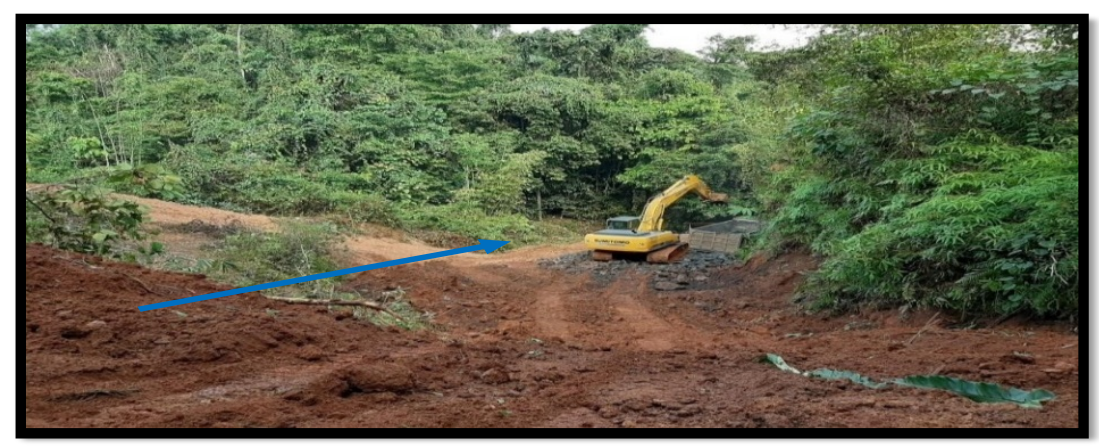

Gambar 3. Superelevasi aktual pada jalan tambang 
b. Jari-jari Tikungan Minimum

Untuk mengetahui jari-jari tikungan minimum, diperlukan beberapa tahap pengambilan data, yaitu mengetahui jari-jari tikungan aktual dilapangan, mencari nilai superelevasi aktual dan mencari nilai koefisien gesek maksimum. Untuk mengetahui jari-jari tikungan aktual di lapangan, maka perlu dilakukan pengukuran secara terbuka di lokasi penelitian dengan alat survei yang selanjutnya data dari hasil survei diolah oleh perangkat lunak, Berikut ini adalah perolehan nilai dari jari-jari tikungan yang dapat dibuat dengan perhitungan hasil lapangan (table 4)

Tabel 4. Jari-jari tikungan

\begin{tabular}{|c|c|c|c|c|}
\hline Jari-jari & Elevasi & Koefisian & Kecepatan & Jari-jari \\
\hline Aktual & aktual & Gesekan & Rencana & Minimum \\
\hline (R) & $(\mathrm{E})$ & $(\mathrm{F})$ & $\left(\mathbf{V}_{\mathrm{r}}\right)$ & $\left(\mathbf{R}_{\min }\right)$ \\
\hline $\mathrm{m}$ & $\%$ & & $\mathrm{Km} / \mathrm{jam}$ & $\mathrm{m}$ \\
\hline 74 & 2,9 & 0,180 & 17 & 11 \\
\hline 37 & 4,8 & 0,182 & 15 & 10 \\
\hline 35 & 9 & 0,179 & 20 & 18 \\
\hline 64 & 8 & 0,175 & 25 & 28 \\
\hline 165 & 1,3 & 0,180 & 17 & 13 \\
\hline 85 & 8 & 0,150 & 29 & 47 \\
\hline
\end{tabular}

Besarnya hasil nilai jari-jari tikungan minimum yang didapatkan tergantung dari nilai superelevasi aktual di lapangan dan nilai kecepatan rencana. Semakin besar nilai superelevasi dan kecepatan rencana, maka akan semakin besar pula nilai jari-jari tikungan minimumnya.

Agar luput dari peluang terjadinya kecelakaan. oleh karena itu, untuk kecepatan yang sudah ditentukan dapat dihitung dengan jari-jari minimum (Rmin) dengan memperhitungkan faktor kecepatan alat angkut, gesekan roda ban dengan permukaan jalan dan superelevasi, maka rumus jari-jari tikungan, di mana Untuk kecepatan rencana $<$ $80 \mathrm{~km} / \mathrm{jam}, \mathrm{f}=(-0.00065 \mathrm{~V})+0.192$

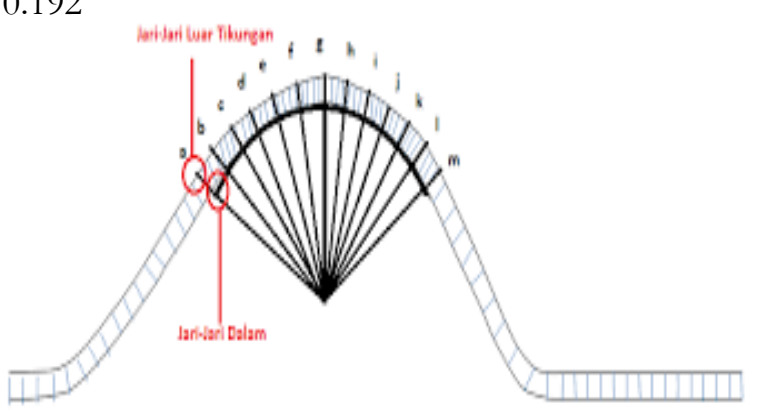

Gambar 4. Jari-jari tikungan aktual di jalan tambang

\section{Jarak Pandang Henti}

Berikut adalah hasil nilai jarak pandang henti (table 5) berdasarkan hasil dari pengamatan dengan menggunakan kurva kaufman \& ault.

Tabel 5. Nilai jarak pandan henti

\begin{tabular}{ccc}
\hline Kemiringan & Kecepatan & Jarak Pandang Henti \\
\hline$(\%)$ & $\mathrm{km} /$ jam & $(\mathrm{m})$ \\
\hline 15 & 40 & 90 \\
10 & 40 & 67 \\
11 & 40 & 70 \\
13 & 40 & 76 \\
15 & 40 & 90 \\
13 & 40 & 76 \\
11 & 40 & 70 \\
\hline
\end{tabular}

Jarak pandang dapat berubah mengikuti grade yang di hasilkan, oleh sebabnya kecepatan pada dump truck Mitsubishi tipe 220PS 6x4 memiliki kecepatan standar $40 \mathrm{~km} /$ jam pada area pertambangan. 


\section{Kemiringan Jalan (Grade)}

Dari hasil pengolahan data berdasarkan persamaan 4 maka terdapat beberapa nilai kemiringan aktual yang tidak memenuhi standar maksimum sebesar $10 \%$.

Tabel 6. Nilai kemiringan jalan

\begin{tabular}{cccccc}
\hline Z1 & Z2 & $\begin{array}{c}\text { Beda } \\
\text { Tinggi }\end{array}$ & $\begin{array}{c}\text { Jarak } \\
\text { Datar }\end{array}$ & \multicolumn{2}{c}{ Kemiringan } \\
& $\mathrm{m}$ & $\mathrm{m}$ & $\mathrm{m}$ & $\%$ & $\left({ }^{\mathrm{O}}\right)$ \\
\hline $\mathrm{m}$ & 927,37 & 10 & 66 & 15 & 8,5 \\
937,46 & 930,26 & 10 & 101 & 10 & 5,7 \\
940,26 & 910,15 & 10 & 88 & 11 & 6,3 \\
920,20 & 889,89 & 8 & 60 & 13 & 7,4 \\
898,26 & 878,74 & 9 & 59 & 15 & 8,5 \\
887,38 & 871,68 & 7,06 & 51 & 13 & 7,4 \\
878,74 & 850,26 & 10 & 91 & 11 & 6,3 \\
860,26 & & & & & \\
\hline
\end{tabular}

\section{SIMPULAN}

Berdasarkan hasil dari perhitungan penelitian ini dapat disimpulkan lebar jalan angkut pada jalan lurus di semua stasiun yaitu 12 meter sampai 13 meter, dan telah memenuhi standar minimum yang ditetapkan yaitu 9 meter. Lebar jalan pada tikungan menurut hasil perhitungan untuk lebar jalan tikungan di setiap stasiun yaitu 12 meter sampai 14 meter, dan telah jalan memenuhi standar minimum yang ditetapkan yaitu 12 meter. Superelevasi jalan aktual tidak memenuhi standar yaitu 1,3\% dan 9\%, sedangkan standar yang ditetapkan untuk superelevasi minimum (4\%) dan superelevasi maksimum (8\%). Kemiringan jalan aktual yang tidak memenuhi standar maksimum $(10 \%)$, dimana kemiringan jalan aktual yang ada di lapangan relatif tinggi yaitu 11\% hingga 15\%.

\section{UCAPAN TERIMAKASIH}

Peneliti mengucapkan terima kasih kepada pihak perusahan pada PT Manakarra Multi Mining Mamuju yang telah memberikan kesempatan dalam melakukan penelitian, dan orang tua tercinta yang senantiasa dengan tulus tanpa henti memberikan dukungan doa, semangat dan nasihat.

\section{REFERENSI}

Aldiyansyah, Aldiyansyah.,2016, "Analisis Geometri Jalan di Tambang Utara pada PT. Ifishdeco Kecamatan Tinanggea Kabupaten Konawe Selatan Provinsi Sulawesi Tenggara", Jurnal Geomine. Vol. 4 No. 1.

Anwar, H., Anshariah, A., Munir, A. S., Umar, E. P., Nurwaskito, A., \& Sanra, S. A. A., 2020. "Mine Haul Road pada PT. Sebuku Iron Lateritic Ores (Silo) Daerah Sebuku”, Jurnal Geosapta. Vol.6 No.1,pp. 1-11.

Firdaus, S. A., Nurhakim, N., Saismana, U., \& Nor, T., 2017, "Perencanaan Tahapan Penambangan Bulanan pada Tambang Terbuka Batubara Metode Open Pit", Jurnal Geosapta. Vol 2 No. 1.

Hartman, H. L., \& Mutmansky, J. M., 2002, “Introductory Mining Engineering”, John Wiley \& Sons.

Indonesianto, Y., 2005, "Pemindahan Tanah Mekanis”, Universitas Pembangunan Nasional Veteran. Jogjakarta.

Kaufman, W. W., \& Ault, J. C., 1978, “Design of Surface Mine Haulage Roads: a Manual. Vol. 8758”, Department of the Interior, Bureau of Mines.

Lambung, T. Y., Saismana, U., Hakim, R. N., \& Fakhturozi, M., 2017, "Evaluasi Jalan Tambang untuk Meningkatkan Produktivitas Alat Angkut pada Aktivitas Pemindahan Overburden”, Jurnal Geosapta. Vol. 2 No 2.

Pelu, A. H., Sudiyanto, A., Cahyadi, T. A., \& Munandar, A.,2018, "Rancangan Teknis Kemajuan Penambangan Andesit Jangka Pendek di Kuari PT Holcim Beton Kecamatan Rumpin Kabupaten Bogor Jawa Barat", Jurnal Geomine. Vol 6 No 2.

Rauf, A., 1998, 'Perhitungan Cadangan Endapan Mineral. Fakultas Teknologi Mineral’, Jurusan Teknik Pertambangan Universitas Pembangunan Nasional. Yogyakarta.

Rahman, M. A., Nurhakim, N., Riswan, R., Noure, A. B., \& Joetra, R., 2017, “Analisa Kelayakan Jalan Angkut Tambang Berdasarkan Geometri dan Material Perkerasan Jalan”, Jurnal Geosapta. Vol. 2 No. 2.

Sutirja, M. A. J., Nurhakim, N., Mustofa, A., \& Santoso, E, 2017, “Studi Daya Dukung Batuan Vulkanik Formasi Pitanak untuk Pemanfaatan Jalan Tambang". Jurnal Geosapta. Vol. 3 No.1. 
Jurnal Matriks Teknik Sipil DOI: https://dx.doi.org/10.20961/mateksi.v9i1.47323

ISSN: 2354-8630

E-ISSN: 2723-4223

Vol 9, No 1 (2021): Maret

Sulistianto, B., 2008, “Diktat TA2221 Peralatan Tambang dam Penanganan Material”, Lembaga Afiliasi Penelitian dan Industri Institut Teknologi Bandung. Bandung.

Umum, D. P., \& Marga, D. J. B., 1997, “Tata Cara Perencanaan Geometrik Jalan Antar Kota”, Direktorat Jenderal Bina Marga, Jakarta. 